
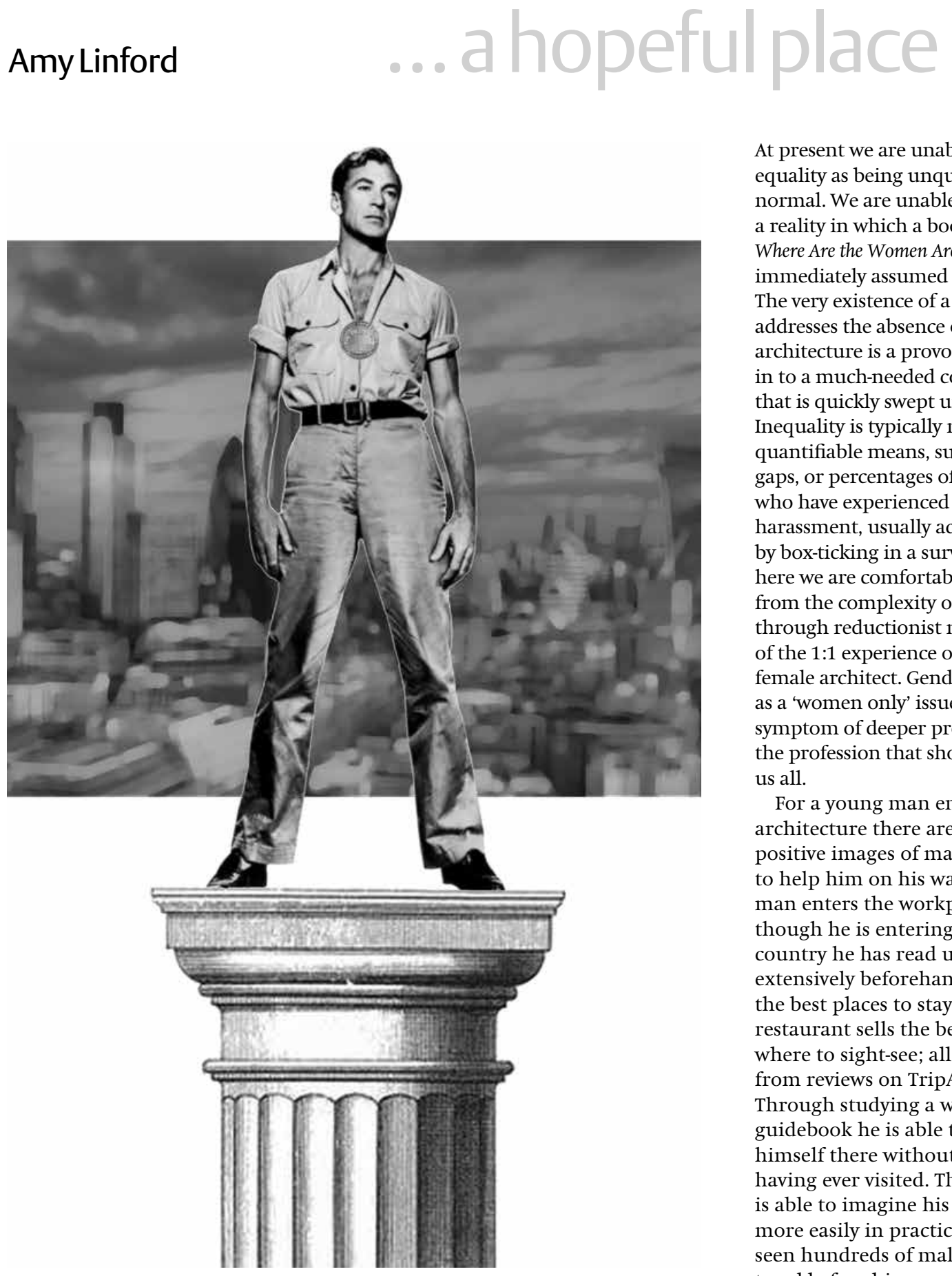

At present we are unable to imagine equality as being unquestionably normal. We are unable to imagine a reality in which a book entitled Where Are the Women Architects? is immediately assumed to be vintage. The very existence of a book that addresses the absence of women in architecture is a provocative leadin to a much-needed conversation that is quickly swept under the rug. Inequality is typically measured by quantifiable means, such as pay gaps, or percentages of women who have experienced sexual harassment, usually accounted for by box-ticking in a survey. From here we are comfortably far away from the complexity of the subject through reductionist measures of the 1:1 experience of being a female architect. Gender is treated as a 'women only' issue yet it is a symptom of deeper problems within the profession that should concern us all.

For a young man entering architecture there are many positive images of male architects to help him on his way. A young man enters the workplace as though he is entering a foreign country he has read up on extensively beforehand: he knows the best places to stay, which restaurant sells the best oysters, where to sight-see; all from reading from reviews on TripAdvisor. Through studying a well-written guidebook he is able to place himself there without actually having ever visited. The young man is able to imagine his future role more easily in practice; having seen hundreds of male architects tread before him as examples of what is possible and leaving a

The heroic architect, Howard Roark of Fountainhead, a making of Hollywood fantasy and wishful thinking in a challenging profession. 
done, from a male perspective. Entering practice as a female is somehow like entering a foreign country with significantly fewer preparations. There is no guidebook and the map is rudimentary and out of date. Getting around requires asking the locals who don't speak your language and asking for directions becomes a tall order. There lies a potential value in being an intrepid explorer; as long as it is recognised and rewarded as a positive divergence by the brave. For most, being able to imagine yourself in a future position helps if there is someone there to relate to. They are there, those brilliant women architects, they are just not as present in architectural media and education as they ought to be.

The subject brings up the presumed conditions that attempt to explain the lack of female success: being able to give birth, not being ambitious enough, being too soft / beautifully distracting for the construction site, and other such myths that crumble under scrutiny. Despina Stratigakos picks apart and debunks many of these myths in her recent book (Review, pp. 178-181) so that we can get on with holding a meaningful discussion. I was pre-warned about these myths by an older male tutor and practitioner as I was finishing my undergraduate studies. It was a statement delivered as a truth intended to prepare me for the injustice. The message was clear: architectural practice is a man's world and a woman's space in it will be limited. Myths thus have a danger of becoming self-fulfilling prophecies.

The statistics are one way of understanding the situation but should the aim be for a fifty-fifty split between women and men in architecture? It appears to me a reductionist approach, a selfconscious attempt to record and treat the symptoms of the problem that are usually measured late in the game in practice. No effort is too late but gender balance is an issue in the workplace that is a product years in the making; having become rigid through messages reinforced in childhood. Despina Stratigakos's 'Architect Barbie' is a mass-produced toy designed to deliver an alternative message much earlier on for more malleable children. It is a small example but one that makes other moves more likely; it enables girls and boys to imagine women architects as something normal. Architect Barbie's presence in popular culture is important to the architecture profession.

The qualitative data, or the anecdotes of being a practising female, become a pile of personal stories that heap up rapidly. I've seen a young woman harassed by a male superior who was later made redundant because she refused to go to bed with him on a business trip. A woman preparing for maternity leave but then was also made redundant because she was a 'part-timer'. These accounts are discounted as nothing more than personal stories and the worst offenders are often those in positions that avoid the consequences. The cases are treated separately as if they are one-offs; the elephant in the room remains. If architectural practice were in a courtroom on trial this would be a dossier of witness statements that would be impossible to ignore.

Being a young female in architecture has led to particular professional experiences that overlap with the personal in interesting but mostly disturbing ways. These range from casual complaints about consultants' own wives in business meetings to myself experiencing sexual harassment within two months of my first job. You feel bemused on the one hand and violated on the other. These personal stories are easy to dismiss due to their private nature and singularity; stories of discrimination are an alarmingly normal office affair. Blaming the individuals involved is easier than taking a critical look at the larger structures at play.

The issue I have when we talk about gender is to do with male frames of reference used when determining success in architectural practice. It is also irrelevant to almost every man simply by being absurdly macho; caricatures of architects such as Howard Roark of The Fountainhead. At its most extreme, the idea of success is based on a figure like this unrealistic depiction; a fictional character of Hollywood fabrication who suffers and causes suffering for his work. This solo hero is placed on a pedestal and is finally recognised for his uncompromising genius and becomes untouchable. It is a position so divorced from the reality of the construction industry, from the real role of the architect and the context in which architects operate. So why then is this idea of success still upheld? Does it give the architect more power than society affords us?

The way that prizes are awarded in architecture is not far from being a search for the next Roark, makers of iconic architecture. Obvious objects of architecture that look like intentionally designed things: skyscrapers in sculptural and sometimes awkward forms that are monuments to architectural culture in themselves. Even when they are criticised as an empty form of architecture, they serve as public relations material for the next large multi-million pound project. The 'successful' architect is often just a good businessman. The way we reward architecture is exclusive, as is the nature of prize giving, but it becomes limited by operating in this uber-male paradigm. It's problematic because there are many forms of architecture and ways of practising that are equally, if not more valuable that are not made exemplar, nor rewarded for their contributions to the profession, and more importantly wider society. There are examples of practice that operate outside of the Roark paradigm (Assemble are a recent example) but what other architectures and forms of practice are we missing out on when we measure 'success' in architecture in such limited ways?

How would a female paradigm of architecture operate? An 'uberfemale' version would be equally as unnerving as her male counterpart I'm sure. Imagine how differently a female architect's collective idea of success would be defined if this were done without any knowledge of existing preconceptions of architectural quality? Other forms of architecture and practice that bring up other ideas of success struggle to exist in a profession that rigidly holds on to what it believes makes a successful architect and assumes 'otherness' is inferior. This is also evident in the prominence of the architect as author of a project, ignoring the large body of professionals, labourers, clients, and stakeholders that have had their parts to play and without whom the project would not exist. Architecture comes awkwardly into being in the real world when it denies the reality of the world in which it comes into existence. 
Architecture is suffering from becoming marginalised and disenfranchised. In numerous casual conversations, I realise that people have not understood what an architect is or what they do. In the wider world, beyond the niche of creatives and academics, it appears that the profession is not well understood or valued. Architects have also had the recent misfortune of being disproportionately blamed for insensitive redevelopment projects masquerading as regeneration; they are of course complicit parties but it is the developers who hold much of the power. The role of the architect in the traditional sense has been eroded by undercutting fees, specialist consultants managing projects, and anxietydriven procurement methods. It is both startling and indeed foolish that within this marginalised and precarious position that nonsensical divisions continue to exist. We miss out as professionals and we miss out as citizens. The paradigms we operate in are unrepresentative of the richness of our society and we are poorer for not addressing the problem as a shared endeavour.

\section{Illustration credits}

arq gratefully acknowledges: Author, 1

\section{Author's biography}

Amy Linford is an architect at muf architecture/art in London. She is involved in a variety of projects including public realm design, master-planning, writing design guidance, exhibition design, and public art works.

\section{Author's address}

Amy Linford

a.l.linford@gmail.com 